\title{
CONSIDERAÇÕES SOBRE O ARGUMENTO DA LADEIRA ESCORREGADIA E SEU USO NA BIOÉTICA ${ }^{1}$ \\ CONSIDERATIONS ON THE ARGUMENT OF SLIPPERY SLOPE AND ITS USE IN BIOETHICS
}

\section{Clarice Rosa Machado² e Diego Carlos Zanella ${ }^{3}$}

\section{RESUMO}

O presente artigo apresenta algumas noções acerca da argumentação para fornecer ao leitor ferramentas cognitivas para que ele consiga escapar de confusões e enganos que o mau uso do argumento pode causar, mais especificamente, com o estudo do argumento da ladeira escorregadia. Sendo o argumento da ladeira escorregadia um tipo de argumento utilizado de forma recorrente nos discursos com questões relacionadas à vida. A partir disso, expor a necessidade de o ser humano desenvolver a capacidade argumentativa para gerenciar relações interpessoais na atual conjuntura do país. Para tal, o estudo consiste em uma abordagem teórico-conceitual, de caráter filosófico.

Palavras-chave: Bioética; Capacidade argumentativa; Ensino; Falácia.

\section{ABSTRACT}

This article presents some notions about the argument to provide the reader with cognitive tools so that he can escape the confusion and deception that the misuse of the argument can cause, more specifically, if he studies the argument of the slippery slope. The slippery slope argument being a type of argument used on a recurrent basis in speeches with life-related issues. From this, to expose the need for the human being to develop the argumentative capacity to manage interpersonal relations in the current situation of the country. For this, the study consists of a theoretical-conceptual approach, of a philosophical nature.

Keywords: Bioethics; Argumentative ability; Teaching; Fallacy.

\footnotetext{
${ }^{1}$ O trabalho, em uma primeira versão, está publicado nos anais do XXI Simpósio de Ensino, Pesquisa e Extensão - SEPE da Universidade Franciscana.

${ }^{2}$ Licenciada em Filosofia. Mestranda em Ensino de Humanidades e Linguagens, Universidade Franciscana (UFN). Bolsista da Coordenação de Aperfeiçoamento de Pessoal de Nível Superior (CAPES). E-mail: clarice.r.machado@gmail.com

${ }^{3}$ Doutor em Filosofia. Professor do Curso de Filosofia e do Mestrado em Ensino de Humanidades e Linguagens, Universidade Franciscana (UFN). E-mail: diego.zanella@gmail.com
} 


\section{INTRODUÇÃO}

Acredita-se que os sujeitos teriam maior êxito em sua vida, no campo pessoal e profissional, ao gerenciarem melhor suas relações com as pessoas que os rodeiam. Para gerenciar as relações é preciso saber argumentar, capacidade importante para o relacionamento interpessoal. Deste modo, a argumentação, junto com a habilidade de compreender e comunicar ideias e emoções, tornaram-se fundamentais para uma boa convivência em sociedade. Haja vista que, sempre que os sujeitos desejam expor o pensamento e sua visão de mundo, eles procuram convencer os seus interlocutores através da argumentação.

Cabe, neste instante, realizar alguns esclarecimentos sobre a argumentação, de modo especial, quando se fala sobre convencer e persuadir. É parte do conhecimento do senso comum utilizar esses termos quando se fala sobre argumentação, mas o que, de fato, se entende por convencer e persuadir? Eles compartilham do mesmo significado? Ao realizar uma busca nos dicionários online de Português, pode ser encontrado esses termos como sinônimos, em ambos os casos, foi encontrado, por exemplo, a seguinte frase "Fazer com que alguém se convença sobre a necessidade de alguma coisa". Talvez, este seja um dos motivos dos sujeitos empregarem os termos 'convencer' e 'persuadir' como similares, e consequentemente, tenham uma má compreensão.

À vista disso, propõe-se a elucidar que argumentar é a arte de convencer e persuadir, mas que essas possuem diferenças que podem atrapalhar a interpretação do argumento, se o leitor não possui este conhecimento. Neste sentido, Abreu (2003, p. 25) afirma que "convencer é construir algo no campo das ideias, isto é, quando convencemos alguém, esse alguém passa a pensar como nós", ou seja, convencer é falar à razão do outro, gerenciando as informações disponíveis para provar ou demonstrar por meio do oferecimento de razões. No que se refere a persuasão, "é construir no terreno das emoções, é sensibilizar o outro para agir. Quando persuadimos alguém, esse alguém realiza algo que desejamos que ele realize" (ABREU, 2003, p. 25).

Diante do exposto, pode-se dizer que as distinções entre convencer e persuadir ocorrem na área em que elas atingem para fazer o outro agir sob nosso comando. O convencimento fala a razão do outro, isto é, tenta-se oferecer razões que sustentam a posição defendida por meio de provas racionais. No caso da persuasão, se busca atingir o outro por meio da emoção, fazendo com que o interlocutor se sensibilize com a argumentação e faça ou aceite o que foi proferido.

Abreu (2003) argumenta que tudo o que é pensado ou realizado é fruto dos discursos que constituem os sujeitos. Na sociedade as pessoas são formadas por meio dos discursos sejam eles político, científico, jurídico, religioso ou do senso comum. Isso pode ser notado em atividades comuns do dia a dia, tais como, por exemplo, parar o carro diante de um sinal vermelho, porque essa atitude

\footnotetext{
${ }^{4}$ Link para o Dicionário de online de Português utilizado para as buscas dos termos convencer e persuadir: https:// www.dicio.com.br/.
} 
foi estabelecida pelo discurso jurídico das leis de trânsito. É preciso fundamentar de forma consistente as decisões tomadas, independentemente da situação, construindo uma ferramenta conceitual de interpretação da realidade.

Desta forma, a argumentação mostra-se importante, porque é uma ferramenta que auxilia os indivíduos a pensar por si próprios, a criticar, a questionar coisas que não entendem, as leis com as quais não concordam, e os ajuda a, inclusive, buscar seus direitos. Assim, ter o conhecimento acerca das noções básicas de argumento, bem como dos bons fundamentos para o pensamento e para a ação, devem ser empregadas por qualquer pessoa (GEACH, 2013).

Com base nisso, entende-se que a educação deve ser organizada para ajudar as pessoas a compreender a própria natureza humana e sua relação com o mundo. E, também, munir os estudantes de ferramentas que permitam que atuem na sociedade com autonomia, criticidade e responsabilidade, exercendo seus direitos e deveres. Para tal, a humanidade precisa de uma sabedoria que guie ou forneça o conhecimento de como utilizar o conhecimento que está disponível para o bem social, a sobrevivência humana e melhor qualidade de vida de todos os seres vivos.

A partir dessas ponderações, tem-se como objetivo, inicial, apresentar a estrutura básica de um argumento para fornecer ao leitor ferramentas para que ele consiga escapar de confusões e enganos que o mau uso ou interpretação errada do argumento pode causar. Tecer algumas considerações acerca da Bioética de Van Rensselaer Potter e sua preocupação com a sobrevivência da espécie humana, para facilitar a compreensão, dentro do contexto, em que se insere o argumento da ladeira escorregadia. Feito este embasamento, busca-se analisar o argumento da ladeira escorregadia, considerando o uso deste tipo de argumento como recorrente nos discursos com questões relacionadas à vida. Os argumentos foram selecionados, tendo como critério temas de destaque no campo da Bioética. Para tal, o estudo consiste em uma abordagem teórico-conceitual, de caráter filosófico.

\section{AARGUMENTAÇÃO E SUA ESTRUTURA BÁSICA}

O ser humano como "ser social e racional, em contato permanente com seus semelhantes, para se defender, para defender seus pontos de vista e até mesmo para sobreviver, sempre teve necessidade de argumentar" (BARBISAN, 2007, p. 111).

A argumentação tem sido objeto de estudo, na área das ciências humanas, desde o século V a.C. No ano de 467, lembra Plantin (1996), Corax e Tisias teriam composto o primeiro "método racional" para falar num tribunal. Todavia, as primeiras reflexões sobre argumentação costumam ser atribuídas a Aristóteles (384-322 a.C.). Sabe-se, porém, que um pouco antes de Aristóteles, os sofistas já se ocuparam da oposição entre discursos (antifonia), do paradoxo, do provável, da dialética como forma de diálogo racional. A interação argumentativa em que se representam as relações sociais proposta pelos sofistas foi criticada pelos platônicos, pois viam na interação pela linguagem uma batalha verbal que ignorava a busca da verdade. Os aristotélicos buscavam verdades, mas verdades científicas, instituindo 
relações entre argumentação e ciência, e por isso tornaram-se críticos da língua natural (BARBISAN, 2007, p. 111-112).

De modo geral, pode-se expor que a argumentação não é decorrente de uma verdade imposta, mas de uma convicção a estabelecer. Entretanto, apesar de alguns pontos comuns, tal como a referência à racionalidade, as diversas teorias argumentativas têm suas divergências. Isso gera certa dificuldade no estabelecimento de um conceito definitivo para a argumentação. Conforme Braatz (2007, p. 140-141) há alguns traços semelhantes entre as teorias explicativas acerca da argumentação formuladas por diversas áreas, os quais são:

i) “argumentar é sempre uma ação relativa à linguagem, quer seja oral, quer seja escrita, na qual se verifica sempre que seu sentido é justificar (ou refutar) uma tese, dando razões para isso. É esse dar razões que diferencia a argumentação das demais formas de resolução de problemas";

ii) "uma argumentação supõe sempre um problema, para o qual há que se encontrar uma solução, suscitando-se assim a necessidade de argumentar";

iii) "há duas formas clássicas de se ver a argumentação, ou seja: como um processo (uma atividade de argumentar) e como um produto, um resultado (os argumentos). No primeiro caso (o processo) é o que ocorre entre o termo inicial (problema) e o termo final (a solução); no segundo, a argumentação vem a ser o conjunto de enunciados, em que se distinguem três elementos: as premissas (de onde se parte); a conclusão (onde se chega) e as inferências (relações entre premissas e conclusões) ";

iv) “a argumentação é sempre uma atividade racional, porque sempre haverá critérios para valorar uma argumentação (isto é, se o argumento é bom ou ruim)".

Nesse viés, Copi $(1978$, p. 23) defende que "argumentar é dar razões para que alguém aceite aquilo que está sendo defendido, ou seja, apresentar evidências, provas e razões para a verdade da conclusão. E, para ser capaz de defender alguma coisa, é preciso ter a capacidade de raciocinar, sobre os diversos temas e acontecimentos que afetam as pessoas, em suas vidas cotidianas, direta ou indiretamente. Nessa perspectiva, julgar criticamente e fundamentar sua crítica, manifestando sua interpretação de determinada situação é uma atividade diária que as pessoas precisam praticar ao assistir o noticiário ou ao ler um jornal. Ao realizar uma crítica, a pessoa revela outras hipóteses, além do seu ponto de vista, que, às vezes, fica escondido, e, para tal atividade é necessário saber argumentar. Além disso, aqueles que têm algum entendimento, sobre argumentos, conseguem diferenciar e perceber essas sutilezas da argumentação.

Outro exemplo são as propagandas, nas quais os comerciais publicitários tentam induzir os futuros clientes para comprarem seus produtos. Eles falam sobre os benefícios e toda a praticidade que o produto irá trazer, e, às vezes, a pessoa até esquece que não precisa, tamanha é a força persuasiva utilizada no argumento da propaganda. Assim, percebe-se que os argumentos são usados cotidianamente nas mais variadas formas em debates (nas escolas, no trabalho, nas mídias, em leituras, filmes, programas de televisão etc.). 
De acordo com Abreu (2003), há algumas condições básicas e importantes da argumentação para que ocorra a compreensão da ideia central e, esta, consiga comunicar algo para o interlocutor. A primeira delas diz respeito ao próprio sujeito que está proferindo o argumento, isto é, quem argumenta precisa ter a tese bem determinada e saber para qual o tipo de problema que esta é a resposta. Uma segunda condição é estabelecer uma linguagem comum com o público para o qual o argumento foi falado, ou seja, quem profere o argumento deve se adaptar às condições sociais e intelectuais de quem o ouve. Outra condição que confere credibilidade para o argumentador é ser honesto, agir de modo ético no processo argumentativo.

O argumento é composto por algumas proposições que servem como "razões", as quais são denominadas de "premissas", e por uma proposição que está sendo defendida, a qual é chamada de “conclusão" (COPI, 1978). Assim, premissas e conclusão formam a estrutura básica do argumento, aquilo que os lógicos chamam de "forma lógica". Quando se estuda essa estrutura, é comum buscar sua forma lógica e, mais ainda, uma vez que se dispõe de sua forma lógica, pode-se fazer críticas que visem a colocar em questão a validade, a solidez e consistência desse argumento. Um modelo de forma lógica muito utilizada em argumentos é, por exemplo, a seguinte: premissa 1: "todo A é B"; premissa 2: "todo B é C"; logo, conclusão: "todo A é C".

\footnotetext{
Argumento é construção intelectual, que segue uma ordem própria, servindo-se de materiais conceituais dados pelas diversas experiências humanas. Argumentar é estruturar esses materiais. A estruturação destes materiais é que torna possível diferenciar um argumento logicamente válido ou correto de uma falácia ou sofisma (KELLER; BASTOS, 2011, p. 45).
}

Por este motivo, é importante ter o conhecimento sobre a estrutura de um argumento, ou seja, considerando aquela proposição que se pretende que seja aceita (conclusão) e as demais proposições (premissas) que tornam essa conclusão aceita. Dispondo do conhecimento sobre o que é um argumento e sua estrutura básica, pode-se criticar um argumento, dizer que ele é falacioso ou inclusive inválido, se esse for o caso, pois é preciso apresentar justificativas coerentes para as críticas realizadas. Ser possuidor de tal conhecimento é extremamente necessário para analisar argumentos e elaborar tal crítica.

Existem argumentos que possuem uma força persuasiva enorme, mas apenas ser persuasivo não equivale, do ponto de vista da lógica, a ser válido, consistente ou verdadeiro. Assim, um argumento pode ser persuasivo, mas isso não significa, por si só, que ele seja um bom argumento. Ao aceitar, somente, que a força persuasiva seja o que qualifica o argumento como bom, então seria necessário concordar que as falácias também são argumentos bons e válidos, visto que muitas vezes são mais persuasivos.

A persuasão é a capacidade ou o ato de convencer alguém a fazer alguma coisa ou de aceitar uma determinada ideia. Para um argumento ser considerado um bom argumento - do ponto de vista lógico - ele precisa ter mais do que apenas força persuasiva, ele precisa ter coerência lógica, pois essa característica é que qualificará sua validade. Um discurso argumentativo pode ser persuasivo, mas um discurso persuasivo nem sempre é argumentativo. A argumentação envolve a razão e a persuasão 
envolve por exemplo, a indução do ouvinte a aceitar o argumento por conta das credenciais de quem o profere. Diante dessa aproximação sobre alguns conceitos acerca da argumentação e da lógica, pode-se iniciar o estudo sobre o argumento conhecido como "ladeira escorregadia".

\section{NOTAS INTRODUTÓRIAS À BIOÉTICA}

No Brasil, a Bioética se iniciou na última década do século XX, atraindo pesquisadores, cientistas de diferentes áreas do conhecimento. Trata-se de um ramo de estudo interdisciplinar que problematiza questões relacionadas às condutas dos seres humanos em relação aos semelhantes e outras formas de vida. Ela surgiu devido a emergência de evitar os horrores que aconteceram nos campos de concentração e técnicas que ferissem, de alguma forma, os princípios vitais dos seres vivos. Além disso, a Bioética procura evitar que algumas formas de vida sejam consideradas inferiores a outras. Orienta sobre os cuidados e limites necessários para lidar com os animais, pois estes, assim como o humano, é dotado de sentido e capaz de sofrer.

Alguns temas e casos que envolvem a Bioética são as polêmicas em torno do aborto, do transplante de órgãos, dos transgênicos, do uso de animais e humanos em experimentos, do uso de células-tronco, da eutanásia, do suicídio, da fertilização in vitro, entre outras. Devido a sua abrangência e os debates ultrapassarem os muros das academias, este campo tem despertado o interesse de estudantes universitários ou recém-formados, isto é, um público jovem (SGANZERLA, 2016). Para os fins deste trabalho, em que o intuito não é se aprofundar no estudo de Bioética, mas apresentar algumas noções importantes para compreender a escolha de argumentos da ladeira escorregadia com exemplos de temas árduos para a Bioética, foi selecionado o texto Bioética: Ponte para o Futuro de Van Rensselaer $\operatorname{Potter}^{5}$ (2016).

Na contracapa do livro Bioethics: bridge to the future, em 1971, Potter, com o intuito de chamar a atenção para o problema escreve:

Ar e água poluída, explosão populacional, ecologia, conservação - muitas vozes falam, muitas definições são dadas. Quem está certo? As ideias se entrecruzam e existem argumentos conflitivos que confundem as questões e atrasam a ação. Qual é a resposta? O homem realmente está colocando em risco o seu meio ambiente? Não seria necessário aprimorar as condições que ele criou? A ameaça de sobrevivência é real ou se trata de pura propaganda de alguns teóricos histéricos?

"Potter define a bioética como a "ciência da sobrevivência humana". Ele traçou um itinerário que vai desde a intuição da criação do neologismo, em 1970, até a possibilidade de encarar a bioética

\footnotetext{
${ }^{5}$ (27/08/1911- 06/09/2001). Foi um bioquímico americano e pesquisador na área de oncologia. A sua experiência com pacientes com câncer proporcionou a ele, correlacionar a ética com a ciência biológica, estabelecendo um diálogo entre a ciência da vida (Bios) e a sabedoria prática (Ethos). Trabalhou por mais de cinquenta anos no MacArdle Laboratory for Cancer Research, na Universidade de Wisconsin e tornou-se presidente da Sociedade Americana de Pesquisa sobre o Câncer, em 1974.
} 
como uma disciplina sistêmica ou profunda, em 1988" (PESSINI, 2016, p. 13). A Bioética potteriana é construída com base em quatro tipos de pontes, as quais são: i) ponte entre o presente e o futuro, uma abordagem focada em interesses de longo alcance e com o objetivo de salvaguardar a sobrevivência da humanidade; ii) ponte entre ciência e valores, como uma disciplina que combina o conhecimento biológico com o conhecimento dos valores humanos; iii) ponte entre natureza e a cultura, aplicando o conhecimento científico em realidades biológicas e a natureza dos seres humanos para favorecer a evolução cultural e iv) ponte entre o ser humano e a natureza, um nova ética que considera a ciência da ecologia e os seres humanos de forma relacionada com o meio ambiente.

A Bioética trata tanto de questões relacionadas ao meio ambiente quanto aos animais humanos e não humanos, isto é, ela concerne sobre a moralidade das ações humanas que podem afetar de forma irreversível a vida dos seres vivos. Assim, ela tenta solucionar os dilemas a partir dos seus quatro princípios, sabendo que não há uma resposta que possa ser julgada como correta, mas fazer com que o profissional reflita sobre sua ação (POTTER, 2016).

Os princípios são da não-maleficência; da beneficência; da autonomia e da justiça. O princípio da não-maleficência, consiste na proibição de causar qualquer dano intencional ao paciente ou cobaia (no caso de testes científicos). O princípio da beneficência está pautado no juramento de Hipócrates ${ }^{6}$, em que se é afirmado que o médico deve visar ao benefício do paciente. A autonomia, diz respeito à capacidade de cada indivíduo de tomar suas próprias decisões, pois esse é o responsável por si, e é ele que decide se quer ser tratado ou se quer participar de um estudo científico. E, por fim, o princípio da justiça visa a criar um mecanismo que regula a relação entre o paciente e o médico, não cabendo está à submissão do profissional.

Para além disso, a Bioética está presente no cotidiano, no meio ambiente, nas relações humanas, no respeito à autonomia dos sujeitos, no modo como consumimos e usufruímos dos recursos naturais, no lugar e na forma como dispensamos o lixo. Neste viés, a Bioética, promove uma reflexão sobre os usos dos recursos naturais e das tecnologias, as consequências do uso excessivo e irrefletido, para que se construa ou seja resgatado o sentimento de respeito e responsabilidade por todos os seres vivos sem nenhuma discriminação.

\section{O ARGUMENTO DA LADEIRA ESCORREGADIA}

O argumento da ladeira escorregadia ou declive escorregadio é considerado por muitos filósofos como ineficiente, pois sua conclusão não possui detalhes que explicam por que essa deve ser a conclusão. Mesmo assim é utilizado constantemente nos debates políticos, ou em campos que tratem de questões sociais. Segundo Goldim (2004, p. 1) o Slippery Slope “ocorre quando um ato particular,

\footnotetext{
${ }^{6}$ Hipócrates (460 a.C. - 370 a.C.) é considerado por muitos uma das figuras mais importantes da história da Medicina, frequentemente considerado o "pai da medicina". O juramento de Hipócrates é uma declaração solene tradicionalmente feita por médicos por ocasião de sua formatura, considerado um patrimônio da humanidade por seu elevado sentido moral.
} 
aparentemente inocente, quando tomado de forma isolada, pode levar a um conjunto futuro de eventos de crescente malefício".

A ladeira escorregadia é um argumento que expõe que, ao conceder que algo aconteça ou que tenha seu início, esse ato ocasionará novos acontecimentos, e posteriormente outra coisa dar-se-á, e assim por diante. Por esse motivo, utilizar-se-á alguns argumentos sobre o aborto e a eutanásia, temas que possuem destaques no campo da Bioética. O tema do aborto é um assunto delicado e aquele sobre o qual mais se tem escrito, debatido e realizado congressos científicos e discussões públicas.

Questões envolvendo a vida estão frequentemente presentes nos debates éticos, como por exemplo, "o feto é uma pessoa?", e "é correto tirar a vida de uma pessoa, mesmo ela estando com uma doença terminal? " etc. É importante salientar que, neste trabalho, pretende- se apenas, usar alguns recortes de argumentos sobre o aborto e a eutanásia para exemplificar o que é o argumento do declive escorregadio e mostrar sua estrutura, mas não discutir questões de ser ou não a favor do aborto e da eutanásia.

Neste tipo de argumento, pretende-se induzir o leitor a acreditar que a ocorrência de um determinado fato desencadeia outros fatos acessórios e, nesse sentido, fatos não calculados no primeiro fato vão ocorrer "descendo ladeira abaixo" até que se chegue em uma situação indesejável a qual não teria mais volta. Essa sucessão de acontecimentos pode ser percebida quando Volokh (2003, p. 1029) diz que “todos podem identificar as situações em que o apoio de um grupo a um primeiro passo A tornou mais fácil para outros implementar o passo B posterior”. Note-se que este é um argumento de forma simples, que, caso se adote uma ou mais mudanças particulares nas ações, esse evento causará um deslizamento que não possui fim, ao menos não um fim agradável. Uma explicação técnica sobre o argumento é:

O declive escorregadio é um tipo de argumento que começa quando somos levados a reconhecer que uma diferença entre duas coisas não é significativa. Depois disso, pode ser difícil negar que a mesma diferença, entre a segunda coisa e a terceira, também não é significativa. Quando esse tipo de argumento começa, pode ser tarde demais para detê-lo: entramos no declive escorregadio (WALTON, 2012, p. 369).

Em outras palavras, o argumento da ladeira escorregadia ocorre quando uma determinada proposição é aceita, e depois desse passo há uma sequência de acontecimentos inevitáveis que decorrem do mesmo, como por exemplo, “[...] uma proposta em prol da legalização do aborto em certos casos poderia ser criticada como o argumento de que tal passo levaria à perda de respeito pela vida humana, o que acabaria levando a campos de concentração para a eliminação de pessoas que não são úteis à economia" (WALTON, 2012, p. 31).

A força persuasiva desse tipo de argumentação é muito forte, porque ela busca distrair quem está ouvindo, fazendo com que este perca o foco do assunto em questão e mantenha a atenção em uma posição que tenha consequências desagradáveis. A falha desse argumento é considerar que ao aceitar um determinado acontecimento, necessariamente acontecerão outros eventos trágicos. Contudo, de um ponto 
de vista estritamente lógico, não há razão para pensar desse modo, por esse motivo é considerado um raciocínio errado. Quando se está diante de um argumento como esse, é preciso realizar uma análise realista do que há de diferente de um acontecimento para os outros com o intuito de evitar injustiças. Com essa avaliação racional as pessoas se tornam capazes de chegar a uma conclusão e verificar se há diferenças, mesmo que poucas, dessas ocorrências, e assim evitar o declive.

Há, em muitos casos de argumentação em declive escorregadio, um espaço legítimo para ataque e defesa, já que no caso de qualquer regra ou norma social, legal ou organizacional, temos razão de exigir regras justas que se apliquem igualmente a todas as pessoas que nelas se encaixem. Mas exigimos também que as regras não sejam aplicadas de maneira rígida por uma burocracia cega. Quando uma avaliação racional nos leva a concluir que um caso é suficientemente diferente para se qualificar como algo excepcional, então exigimos que a regra seja quebrada. A questão é até que ponto um caso é semelhante ao outro (WALTON, 2012, p. 371).

A forma técnica do argumento do declive escorregadio é modus ponens, que segue a presente estrutura i) "Se P, então Q"; ii) "P"; iii) "Portanto, Q", ou pode ser representada como $((\mathrm{P} \rightarrow \mathrm{Q}) \wedge \mathrm{P}) \rightarrow \mathrm{Q}$. Para melhor entender a forma do argumento na linguagem informal, pode-se utilizar o seguinte exemplo: i) Se a legalização do aborto for aceita, então a eutanásia será do mesmo modo; ii) A legalização do aborto foi aceita; iii) Portanto, a eutanásia também será. Um outro exemplo sobre o debate acerca do aborto, é o seguinte: se permitirmos o aborto de fetos com anencefalia, em pouco tempo permitiremos o aborto de fetos portadores de deficiências físicas, e em seguida de fetos com alguma doença e quaisquer fetos que sejam considerados indesejáveis. Em decorrência disso, toda a proteção à vida intrauterina estará perdida.

Uma objeção referente ao uso do argumento da ladeira escorregadia pode ser, atentar para a diferença entre o caso inicial e os casos que se seguem. Por exemplo, nos debates sobre o aborto, pode ser argumentado que é preciso olhar caso a caso, uma vez que, certamente, se encontrará motivos para que os pais não queiram levar adiante a gravidez, principalmente se forem adolescentes. Então, mesmo que possa parecer que os casos são todos muito semelhantes, quando se faz uma análise mais cuidadosa, percebe-se que desanalogias e diferenças podem ser encontradas (por exemplo, pode ser argumentado que - no caso dos fetos anencefálicos - encontra-se algumas particularidades, a saber, estes não têm formação cerebral completa, eles não podem sentir como outros fetos sentem etc.). Uma vez que as diferenças são encontradas, verifica-se que a argumentação, diferentemente do que foi afirmado na ladeira escorregadia, não serve para todos os casos de aborto de fetos, portanto, é notável que não há razão para aceitar que esse tipo de aborto se aplica a todos os outros casos.

Deste modo, esse argumento pode ser reconhecido facilmente em um discurso comum quando uma pessoa diz "se aceitarmos x, então, em um determinado momento também aceitaremos y". No que diz respeito à eutanásia, os argumentos contra baseiam-se no princípio absoluto da sacralidade da vida. Segundo este princípio, a vida é um bem que foi concedido pelo Criador, por este motivo é considerada sagrada e em nenhum momento pode ser interrompida. 


\begin{abstract}
Segundo esta premissa absoluta, a vida consiste em um bem - concessão da divindade ou manifestação de um finalismo intrínseco da natureza -, possuindo assim um estatuto sagrado - isto é, incomensurável do ponto de vista de todos os "cálculos" que possam, eventualmente, ser feitos sobre ela -, não podendo ser interrompida, nem mesmo por expressa vontade de seu detentor (SIQUEIRA-BATISTA; SCHRAMM, 2005, p. 115).
\end{abstract}

Um outro argumento sobre a sacralidade da vida, que pode ser usado tanto contra o aborto quanto contra a eutanásia é que independente das condições da vida, toda a vida merece ser vivida, pois é um privilégio que a divindade deu ao homem. Assim, identifica-se a relevância de conhecer a estrutura dos argumentos para evitar conclusões precipitadas, bem como evitar o uso de argumentos da ladeira escorregadia nos diálogos. Sendo assim, pode-se dizer que os argumentos contra a eutanásia e o aborto tem uma força persuasiva muito grande, mas são imunes, de um ponto de vista estritamente lógico, à crítica concernente à sua coerência.

\title{
CONSIDERAÇÕES FINAIS
}

Possuir o conhecimento sobre a argumentação é crucial na atual conjuntura político-econômica do país, quiçá, este deve ser um aprendizado essencial para viver bem e com autonomia em sociedade. Então, apresentar algumas noções acerca da argumentação e esclarecer as diferenças entre os termos convencer e persuadir que são muito recorrentes quando se refere a argumentação, manifestou-se como um estudo necessário. Para além disso, estudar a argumentação através do argumento da ladeira escorregadia com exemplos reais e temas polêmicos para a sociedade pareceu relevante para a melhor compreensão da temática.

Conclui-se que, ter a possibilidade de resolver problemas reais leva as pessoas a serem mais persistentes naquilo que elas se propõem a fazer, e, portanto, apoderar-se de capacidades de lidar com as informações disponíveis via mídias digitais, atuar com discernimento e responsabilidade nas diferentes situações, resolver problemas, ter autonomia para tomar decisões, têm se configurado como aprendizagens essenciais para a vida.

A argumentação é um instrumento necessário para a construção das habilidades cognitivas das pessoas. Acredita-se, que estudar essas "formas lógicas" de argumentos pode ajudar a qualificar a habilidade das pessoas para "dar razões" e, assim, qualificar também suas capacidades de leitura, escrita e debate. Além disso, com esses conhecimentos é possível identificar, nos mais variados meios de comunicação, argumentos enganosos, que muitas vezes costumavam ser aceitos. Ou mesmo, perceber que em alguns momentos são realizadas argumentações errôneas e mal estruturadas.

A forma lógica, ou seja, a estrutura do argumento, permite verificar quando as premissas estão encadeadas de tal maneira que levam à sua conclusão, e quando não levam, bem como encontrar o desafio ou a fragilidade do argumento que está em debate. Contudo, o que é de grande relevância é entender 
que ao aceitar alguns acontecimentos, isso não quer dizer, necessariamente, que os próximos eventos serão ocasionados por essa escolha. Os casos precisam ser avaliados isoladamente, levando em conta seu contexto. Realizar uma análise dos argumentos é imprescindível para evitar conclusões precipitadas e errôneas, bem como entrar em problemas por causa da falta de conhecimento sobre os argumentos.

\section{REFERÊNCIAS}

ABREU, A. S. A arte de argumentar: Gerenciando Razão e Emoção. São Paulo: Ateliê Editorial, 2003.

BARBISAN, L. B. Uma proposta para o ensino da argumentação. Letras de Hoje, Porto Alegre, v. 42, n. 2, p. 111-138, 2007.

BRAATZ, T. H. É preciso argumentar? Reflexões sobre a argumentação jurídica e a teoria de Manuel Atienza. Revista Jurídica, Blumenau, v. 11, n. 21, p. 133-147, 2007.

COPI, I. M. Introdução à lógica. São Paulo: Mestre Jou, 1978.

GEACH, P. T. Razão e argumentação. Porto Alegre: Penso, 2013.

GOLDIM, J. R. Slippery Slope. In: GOLDIM, J. R. Bioética: índice geral de textos, resumos, definições, normas e casos, 2004. Disponível em: https://www.ufrgs.br/bioetica/slippery. Acesso em: 29 out. 2019.

PESSINI, L. Introdução à edição brasileira, Van Rensselaer Potter: a pessoa e o legado. In: POTTER, V. R. Bioética: Ponte para o Futuro. São Paulo: Edições Loyola, 2016.

POTTER, V. R. Bioethics: bridge to the future. Englewood Cliffs: Prentice-Hall, 1971.

POTTER, V. R. Bioética: Ponte para o Futuro. São Paulo: Edições Loyola, 2016.

SGANZERLA, A. Apresentação à edição brasileira. In: POTTER, V. R. Bioética: Ponte para o Futuro. São Paulo: Edições Loyola, 2016.

SIQUEIRA-BATISTA, R.; SCHRAMM, F. R. Conversações sobre a "boa morte": o debate bioético acerca da eutanásia. Caderno de Saúde Pública, Rio de Janeiro, v. 21, p. 111-119, 2005. 
VOLOKH, E. The mechanisms of the slippery slope. Harvard Law Review, v. 116, n. 4, p. 1026-1137, 2003. Disponível em: https://bit.ly/2ClrXzK. Acesso em: 29 out. 2019.

WALTON, D. N. Lógica Informal. 2. ed. São Paulo: WMF Martins Fontes, 2012. 